\title{
Mutual fund performance benchmarking using a quadratic directional distance function approach
}

\author{
Konstantina Pendaraki \\ Department of Business Administration of \\ Food and Agricultural Enterprises, \\ University of Patras, \\ 30100 Agrinio, Greece \\ Email: dpendara@upatras.gr
}

\begin{abstract}
The purpose of this paper is to apply a quadratic directional distance function in order to validate a relative performance indicator for portfolio benchmarking analysis. Based on a daily data set generated from a sample of 43 equity mutual funds the present study compares the performance results given by a directional and two standard distance function models as well as with a traditional fund performance index for periods ranging from 6 months to 4 years. A significant difference was observed in their rankings overall time horizons. This finding implies that ignoring the diversification effect of covariances in portfolio risk reduction and the potential improvements in returns will yield a biased estimate of mutual fund performance.
\end{abstract}

Keywords: financial management; directional distance function; data envelopment analysis; portfolio selection; performance evaluation; mutual funds.

Reference to this paper should be made as follows: Pendaraki, K. (2015) 'Mutual fund performance benchmarking using a quadratic directional distance function approach', Int. J. Financial Engineering and Risk Management, Vol. 2, No. 1, pp.30-47.

Biographical notes: Konstantina Pendaraki is a Lecturer of Financial Management at the Department of Business Administration of Food and Agricultural Enterprises in University of Patras, Greece. She received BSc in Economic Sciences from University of Crete, Greece, in 1994, MSc and PhD in Financial Management from the Technical University of Crete, Greece in 2008 and 2003, respectively. Her main research interests are in the areas of finance, operational research and agricultural economics. She has published in international peer reviewed journals and she has co-authored a book titled Evaluation and Management of Mutual Funds: A Theoretical and Empirical Research (in Greek).

This paper is a revised and expanded version of a paper entitled 'Mutual fund performance benchmarking using a quadratic directional distance function approach' presented at the '4th National Conference of the Financial Engineering and Banking Society', Athens, Greece, 20-21 December 2013. 


\section{Introduction}

The measurement of funds' performance is receiving an increasing interest both from an applied and a theoretical perspective. Indeed, since the pioneering studies of Treynor (1965), Sharpe (1966) and Jensen (1969), many of indices have been introduced and empirically applied to evaluating the performance of mutual funds. However, even though these performance measures have been widely used in the assessment of fund performance, researchers have note several limitations in their application, such as the benchmark error i.e. a ranking inversion is likely to occur whenever a different benchmark is employed (Roll, 1978). Moreover, Ornelas et al. (2009) verify that the choice of the performance measure is important for mutual fund ranking and selection.

Besides the traditional fund performance indicators, a growing body of studies has already used frontier methods as a tool for benchmarking comparisons in portfolio analysis. Based on the assumption that return is desirable while risk is to be avoided, these studies have applied non-parametric efficiency measurement techniques, most prominently Data Envelopment Analysis (DEA) (Charnes et al., 1978) (see, for example, McMullen and Strong, 1998; Morey and Morey, 1999; Galagedera and Silvapulle, 2002; Gregoriou, 2003; Chang, 2004). DEA uses an endogenous benchmarking approach, avoiding problems arising from selecting an appropriate market index as a benchmark. The boundary of the attainable set of funds gives a benchmark relative to which the efficiency of a fund can be measured. Hence, this approach is not based on any theoretical model (CAPM or APM) and provides the opportunity to a fund manager or investor to appraise and rank mutual funds in a risk-return framework without using specific market indices as benchmarks.

Many studies on Greek mutual funds performance evaluation based on traditional fund performance measures have been undertaken. See for example Handjinicolaou (1980), Milonas (1999), Philippas (1999), Sorros (2003), Artikis (2004), etc. Moreover, Pendaraki et al. $(2003,2005)$ and Babalos et al. (2012a, 2012b) evaluate Greek mutual fund performance through multi-criteria analysis, while Pendaraki and Spanoudakis (2012) through argumentation-based decision making theory. However, studies on Greek mutual fund performance benchmarking using DEA are few (see, for example, Alexakis and Tsolas, 2011; Babalos et al., 2012a; Babalos et al., 2012b; Pendaraki, 2012). Most of them apply a standard DEA approach for estimating efficiency; an input-oriented with variable returns to scale DEA version (DEA-BCC: Banker et al., 1984).

Rather than focusing on standard DEA performance measures, in the present study, we employ the directional distance function to estimate fund efficiency. More specifically this work applies a variation of the directional distance function, adopted for portfolio selection by Briec et al. (2004). Unlike the traditional DEA models that optimise solely either in a return augmentation or in a risk contraction orientation, the directional distance function simultaneously optimise in both orientations as much as it is technologically feasible. Moreover, in order to be in line with Markowitz $(1952,1959)$ portfolio concept, a quadratic risk term (variance of returns) is used. Finally, we compare the directional efficiency indicator with two standard BCC-DEA models and a traditional fund performance indicator, i.e. Information Ratio (IR). As far as we know, this is the first work of its kind. 
The rest of the paper is organised as follows. Section two gives some useful notation in portfolio selection while section three describes the distance models employed. Section four describes both the data set and the results obtained. Finally, section 5 concludes the paper.

\section{Efficient frontier and portfolio selection}

Markowitz $(1952,1956)$ developed his portfolio-selection technique, as a mean-variance model where the expected returns and the co-variances of the returns of all involved assets are taken into account for the location of the optimal portfolios.

In order to introduce main ideas of the portfolio selection problem, let us consider a given portfolio of $n$ risky financial assets or funds constructed on the basis of a weight vector $w=\left(w_{1}, w_{2}, \ldots, w_{n}\right)$ with $\sum_{i=1}^{n} w_{i}=1$ and $w_{i}>0$ if short sales are not allowed. The portfolio return is the weighted average return of the funds included in the portfolio, while its variance is equal to the weighted average covariance of the returns on its individual funds.

We compute the expected portfolio returns as follows: $E\left(r_{p}\right)=\sum_{i=1}^{n} w_{i} E\left(r_{i}\right)$, where $\sum_{i=1}^{n} w_{i}=1 ; r_{i}, r_{p}$ is the return on the $i$ fund and portfolio $p$, respectively, and $E\left(r_{i}\right)$ the expectation of the mean return on $i$ fund. The formula of portfolio risk is: $\operatorname{Var}\left(r_{p}\right)=\sigma_{p}^{2}=\sum_{i=1}^{n} \sum_{j=1}^{n} w_{i} w_{j} \operatorname{Cov}\left(r_{i}, r_{j}\right)$, where $\operatorname{Cov}\left(r_{i}, r_{j}\right)$ is the covariance of the returns on the $i$ and $j$ funds.

The Markowitz's optimum portfolio may be calculated according to the following optimisation model.

$$
\begin{aligned}
& \max \mu \sum_{i=1}^{n} w_{i} \mathrm{E}\left(r_{i}\right)-\rho \sum_{i=1}^{n} \sum_{j=1}^{n} w_{i} w_{j} \operatorname{Cov}\left(r_{i}, r_{j}\right) \\
& \text { s.t. } \\
& \sum_{i=1}^{n} w_{i}=1
\end{aligned}
$$

$w_{i} \geq 0$

where $\mu \geq 0$ and $\rho \geq 0$ are risk parameters. The ratio $\rho / \mu \in[0,+\infty]$ represents the degree of absolute risk aversion. In the case where we set $\mu=0$ and $\rho=1$ we minimise only the variance-covariance matrix of the return of portfolio. Although recent studies propose more complex decision models (see for example, Hallerbach et. al., 2004; Bollen 2007; Xidonas et al., 2012), Markowitz's mean-variance model is a widely used portfolio selection model. 


\section{Distance functions in portfolio construction}

\subsection{Standard data envelopment analysis model}

The classical Debreu-Farrell input distance functions have proven useful tools to derive efficiency measures for mutual fund performance benchmarking through various applications of DEA (Charnes et al., 1978) models. Quite frequently, portfolio efficiency studies apply the standard BCC extension (Banker et al., 1984) of the first DEA formulation. Input orientation of the BCC-DEA variant, whose objective is to minimise the risks while returns are kept at least at their current levels, is employed in order to handle potentially negative returns of portfolios through the translation invariant property towards outputs, of this model.

The input BCC portfolio efficiency measure can be calculated by the following program.

$$
\begin{aligned}
& D_{V C}=\min \theta \\
& \text { s.t. } \\
& \sum_{i=1}^{n} w_{i} E\left(r_{i}\right) \geq E\left(r_{i}\right) \\
& \sum_{i=1}^{n} \sum_{j=1}^{n} w_{i} w_{j} \operatorname{Cov}\left(r_{i}, r_{j}\right) \leq \theta \operatorname{Var}\left(r_{i}\right) \\
& \sum_{i=1}^{n} w_{i}=1, \mathrm{w}_{i} \geq 0, i=1, \ldots, n .
\end{aligned}
$$

The $\theta^{*}$ is a scalar and represents the input-oriented efficiency score of the fund under evaluation. By construction the value of $\theta$ lies in the interval $(0,1]$. A fund is efficient if $\theta^{*}=1$; otherwise it is inefficient. One quadratic program is solved for each fund to assess its performance. The left hand sides in the constraints define a composite efficient portfolio which is the benchmark for the inefficient fund under evaluation. The scalars in the right-hand sides are the risk and the return of the fund under evaluation. Thus the output constraint fixes the return level of the efficient portfolio in order to be the same as that of the fund under evaluation. The theta is a multiplier that indicates the distance from the efficient frontier. For the inefficient funds, a projection point into the efficient frontier is defined. The distance between the evaluated fund and its projection point is the efficiency measure.

\subsection{Directional distance function model}

Directional distance function (see Chambers et al., 1998) extended the usual notions of input and output distance functions. It measures the distance to the production frontier in some pre-assigned input-output direction given by a vector. As a result, this function is more flexible than the traditional partial orientation since it permits outputs to increase and inputs decreasing, simultaneously. Additionally, this directional distance function nests the Debreu-Farrell input and output efficiency measures as special cases. Moreover, as an additive measure of efficiency, it is not restricted to non-negative input and output quantities. 
To measure portfolio efficiency, Briec et al. (2004) introduced a variation of the directional distance function that evaluates the performance of portfolios by measuring the distance between a portfolio and an optimal portfolio projection on the Markowitz efficient frontier. Under portfolio context, when risk is approximated with the variance of expected returns, this efficiency distance function may be calculated from the following program.

$$
\begin{aligned}
& \vec{D}_{g}=\max \delta \\
& \text { s.t. } \\
& \sum_{i=1}^{n} w_{i} E\left(r_{i}\right) \geq E\left(r_{i}\right)+\delta g_{E} \\
& \sum_{i=1}^{n} \sum_{j=1}^{n} w_{i} w_{j} \operatorname{Cov}\left(r_{i}, r_{j}\right) \leq \operatorname{Var}\left(r_{i}\right)-\delta g_{V} \\
& \sum_{i=1}^{n} w_{i}=1, \mathrm{w}_{i} \geq 0, i=1, \ldots, n, g \neq 0
\end{aligned}
$$

where $g$ is a vector defining the direction of optimisation. By construction, the value of $\delta$ lies in the half open interval $[0, \infty]$. A fund is efficient if $\delta^{*}=0$; otherwise it is inefficient.

Efficiency estimation depends on the choice of the directional vector. Several directions can be considered. One practical choice includes the unit vector, which implies that all observations will be evaluated in the same direction. When we choose the direction vector to be $g=\left(-g_{V}, g_{E}\right)$, i.e. the same value as the observed input/output bundle, the directional distance functions measure the maximum proportional increase of expected returns simultaneously to a reduction of risks. One quadratic program is solved for each fund in order to assess its performance. For more details of the basic properties about this function see Briec et al. (2004).

\section{Empirical study}

\subsection{Data set}

In 2007, global financial markets were plunged into major turmoil. The uncertainty caused by the rapid international expansion of the financial crisis had a negative impact on all business sectors. The Greek economy has entered a recession since 2009 as a result of the global financial crisis and the following sovereign debt crisis. The economic crisis had also adverse effects on the Greek capital market. In 2010, the General Index of the Athens Exchange fell by $35.62 \%$, as compared to a $22.9 \%$ gain in 2009 , an annual loss of $65.5 \%$ in 2008 and an annual gain of 17.9\% in 2007 (Hellenic Fund \& Asset Management Association). Placements in mutual fund and portfolio investment company shares presented upward and downward trends. The mutual fund market saw reduction of total mutual fund net assets, as outflows strike almost all categories of mutual funds. By the end of 2010, the total net assets of Greek domestic equity mutual funds amounted to 1.9 billion Euros, as compared to 3.0 billion Euros in 2009, 2.6 billion Euros in 2008 and 5.2 billion Euros in 2007 (Hellenic Fund \& Asset Management Association, 2011). 
Under these unstable conditions, where the Greek market has been characterised by major fluctuations, a decrease in stock market prices and continuous inflows and outflows of liquidity in mutual funds placements, we question the usefulness of a market index for benchmarking purposes. Furthermore, in the case that an investor is based upon unstable historical data for current and future fund's performance predictions it seems to us better to choose short estimation periods for the evaluation of a fund's historic performance. Although by going back further in time we get the advantage of having more observations in our analysis, this could be offset by the fact that under high unstable market conditions funds might have dramatically changed their basic characteristics due to mergers, acquisitions or other changes in their investment objectives.

The sample used in the present study is collected from the Hellenic Fund \& Asset Management Association. It consists of daily net asset value data of 43 domestic equity mutual funds over a time period running from January 2007 to December 2010. A total of 42,957observations (43 funds $\times 999$ daily data for the 4 year time horizon 4yrs) is generated and it is being restricted to only observations with non-missing values. For sensitivity analysis four more time horizons were examined spanning from 6 months (6mns), 1 year (1yr), 2 years (2yrs) and 3 years (3yrs) back from December 2010). For each of the 43 funds, we have calculated and annualise their Continuous Compounding (cc) daily returns and their covariance's matrices and variances with daily returns.

Table 1 reports some useful descriptive statistics of the two variables used in the analysis. The examined period contains both bull and bear market sub-periods due to the global financial crisis, that has been ongoing since 2007, and 2010 Greek sovereign crisis. Thus, negative returns and high dispersion of them are presented in all time horizons.

Table 1 Variables' descriptive statistics across different time horizons

\begin{tabular}{lcccccccccc}
\hline & \multicolumn{4}{c}{ Annualised mean of cc daily returns } & \multicolumn{5}{c}{ Annualised variance of cc daily returns } \\
\cline { 2 - 10 } & $6 m s$ & $1 y r s$ & $2 y r s$ & $3 y r s$ & $4 y r s$ & $6 m s$ & $1 y r s$ & $2 y r s$ & $3 y r s$ & $4 y r s$ \\
\hline Mean & -0.014 & -0.365 & -0.074 & -0.348 & -0.224 & 0.047 & 0.083 & 0.080 & 0.088 & 0.072 \\
Std. Dev. & 0.008 & 0.007 & 0.005 & 0.006 & 0.005 & 0.002 & 0.003 & 0.003 & 0.003 & 0.002 \\
Median & 0.003 & -0.380 & -0.074 & -0.350 & -0.224 & 0.047 & 0.083 & 0.080 & 0.087 & 0.071 \\
Min & -0.179 & -0.492 & -0.171 & -0.433 & -0.286 & 0.025 & 0.052 & 0.050 & 0.051 & 0.042 \\
Max & 0.077 & -0.260 & -0.012 & -0.267 & -0.148 & 0.094 & 0.157 & 0.151 & 0.159 & 0.126 \\
\# obs. & 5590 & 10836 & 21543 & 32164 & 42957 & 5590 & 10836 & 21543 & 32164 & 42957 \\
\hline
\end{tabular}

\subsection{Portfolio efficiency results}

We compute the portfolio inefficiencies over the 5 time horizons using the directional distance function (3). Note that most returns are negative in the examined period. In order to overcome this problem, we followed the work of Kerstens and Van de Woestyne (2011). More precisely, we take the direction vector to be $g=\left(-g_{V},\left|g_{E}\right|\right)$, i.e. the same value as the observed variance and the absolute values of the observed returns. Their values and rankings are reported in Table 2. 
Table 2 Directional distance function inefficiencies and their rankings across 5 time horizons

\begin{tabular}{|c|c|c|c|c|c|c|c|c|c|c|c|c|}
\hline \multirow{2}{*}{ Fund } & \multicolumn{5}{|c|}{$\vec{D}_{g}$} & \multicolumn{5}{|c|}{ Rank of $\vec{D}_{g}$} & \multirow{2}{*}{\multicolumn{2}{|c|}{ Sum of Overall }} \\
\hline & $6 m s$ & $1 y r$ & $2 y r s$ & $3 y r s$ & $4 y r s$ & $6 m s$ & $1 y r$ & $2 y r s$ & $3 y r s$ & $4 y r s$ & & \\
\hline mf_01 & 0.213 & 0.341 & 0.558 & 0.229 & 0.338 & 2 & 35 & 32 & 21 & 25 & 115 & 22 \\
\hline mf_02 & 0.796 & 0.471 & 0.747 & 0.382 & 0.481 & 43 & 43 & 43 & 43 & 43 & 215 & 43 \\
\hline mf_03 & 0.546 & 0.405 & 0.511 & 0.343 & 0.413 & 26 & 41.5 & 21 & 39.5 & 38 & 166 & 35 \\
\hline mf_04 & 0.36 & 0.018 & 0.251 & 0.189 & 0.295 & 10 & 2 & 4 & 15 & 16 & 47 & 4 \\
\hline mf_05 & 0.614 & 0.287 & 0.516 & 0.208 & 0.313 & 36 & 21 & 22 & 18 & 18 & 115 & 22 \\
\hline mf_06 & 0.703 & 0.357 & 0.648 & 0.343 & 0.433 & 40.5 & 39 & 41 & 39.5 & 39 & 199 & 41 \\
\hline mf_07 & 0.592 & 0.262 & 0.519 & 0.274 & 0.363 & 30 & 20 & 23 & 26 & 27 & 126 & 27 \\
\hline mf_08 & 0.601 & 0.303 & 0.322 & 0 & 0.003 & 32 & 22 & 6 & 1 & 2 & 63 & 12 \\
\hline mf_09 & 0.286 & 0 & 0.264 & 0.003 & 0.026 & 6 & 1 & 5 & 2 & 3 & 17 & 1 \\
\hline mf_10 & 0.586 & 0.240 & 0.536 & 0.176 & 0.243 & 29 & 15 & 25 & 13 & 8.5 & 90.5 & 17 \\
\hline mf_11 & 0.434 & 0.335 & 0.547 & 0.195 & 0.326 & 12 & 33 & 29 & 16.5 & 22 & 112.5 & 21 \\
\hline mf_12 & 0.534 & 0.261 & 0.538 & 0.295 & 0.408 & 22 & 19 & 26 & 34 & 35.5 & 136.5 & 29 \\
\hline mf_13 & 0.517 & 0.163 & 0.545 & 0.352 & 0.457 & 19 & 7 & 28 & 41 & 42 & 137 & 30 \\
\hline mf_14 & 0.48 & 0.252 & 0.54 & 0.297 & 0.408 & 17 & 17 & 27 & 36 & 35.5 & 132.5 & 28 \\
\hline mf_15 & 0.441 & 0.313 & 0.397 & 0.007 & 0 & 13 & 25 & 10.5 & 3 & 1 & 52.5 & 7 \\
\hline mf_16 & 0.296 & 0.246 & 0.443 & 0.283 & 0.321 & 8 & 16 & 15 & 30.5 & 20 & 89.5 & 16 \\
\hline mf_17 & 0.605 & 0.347 & 0.59 & 0.278 & 0.387 & 34 & 37 & 38 & 28 & 33 & 170 & 37 \\
\hline mf_18 & 0.278 & 0.119 & 0 & 0.218 & 0.3 & 4 & 5 & 1.5 & 20 & 17 & 47.5 & 5 \\
\hline mf_19 & 0.539 & 0.182 & 0.419 & 0.216 & 0.32 & 25 & 8 & 13 & 19 & 19 & 84 & 15 \\
\hline mf_20 & 0.616 & 0.321 & 0.561 & 0.294 & 0.379 & 37 & 30.5 & 34 & 33 & 32 & 166.5 & 36 \\
\hline mf_21 & 0.537 & 0.311 & 0.5 & 0.262 & 0.354 & 24 & 23 & 20 & 23 & 26 & 116 & 24 \\
\hline mf_22 & 0.283 & 0.101 & 0.136 & 0.078 & 0.098 & 5 & 4 & 3 & 5 & 4 & 21 & 2 \\
\hline mf_23 & 0.604 & 0.321 & 0.535 & 0.18 & 0.292 & 33 & 30.5 & 24 & 14 & 15 & 116.5 & 25 \\
\hline mf_24 & 0.703 & 0.354 & 0.598 & 0.266 & 0.377 & 40.5 & 38 & 39 & 24 & 31 & 172.5 & 39 \\
\hline mf_25 & 0.447 & 0.345 & 0.381 & 0.267 & 0.332 & 14 & 36 & 8 & 25 & 24 & 107 & 20 \\
\hline mf_26 & 0.552 & 0.316 & 0.589 & 0.278 & 0.374 & 28 & 27 & 36.5 & 28 & 29.5 & 149 & 33 \\
\hline mf_27 & 0.548 & 0.316 & 0.589 & 0.278 & 0.374 & 27 & 27 & 36.5 & 28 & 29.5 & 148 & 32 \\
\hline mf_28 & 0.383 & 0.138 & 0.407 & 0.168 & 0.277 & 11 & 6 & 12 & 12 & 14 & 55 & 8 \\
\hline mf_29 & 0.338 & 0.209 & 0.478 & 0.099 & 0.263 & 9 & 12 & 18.5 & 6 & 10 & 55.5 & 9 \\
\hline mf_30 & 0.629 & 0.405 & 0.549 & 0.361 & 0.442 & 38 & 41.5 & 30 & 42 & 40.5 & 192 & 40 \\
\hline mf_31 & 0.239 & 0.051 & 0 & 0.152 & 0.243 & 3 & 3 & 1.5 & 9 & 8.5 & 25 & 3 \\
\hline mf_32 & 0.536 & 0.214 & 0.422 & 0.156 & 0.271 & 23 & 13 & 14 & 10 & 12 & 72 & 13 \\
\hline mf_33 & 0.597 & 0.203 & 0.39 & 0.074 & 0.181 & 31 & 11 & 9 & 4 & 5 & 60 & 11 \\
\hline mf_34 & 0.529 & 0.338 & 0.579 & 0.288 & 0.389 & 21 & 34 & 35 & 32 & 34 & 156 & 34 \\
\hline
\end{tabular}


Table 2 Directional distance function inefficiencies and their rankings across 5 time horizons (continued

\begin{tabular}{|c|c|c|c|c|c|c|c|c|c|c|c|c|}
\hline \multirow{2}{*}{ Fund } & \multicolumn{5}{|c|}{$\vec{D}_{g}$} & \multicolumn{5}{|c|}{ Rank of $\vec{D}_{g}$} & \multicolumn{2}{|c|}{ Sum of Overall } \\
\hline & $6 m s$ & $1 y r$ & $2 y r s$ & $3 y r s$ & $4 y r s$ & $6 m s$ & $1 y r$ & $2 y r s$ & $3 y r s$ & $4 y r s$ & & \\
\hline mf_35 & 0.466 & 0.236 & 0.397 & 0.283 & 0.324 & 16 & 14 & 10.5 & 30.5 & 21 & 92 & 18 \\
\hline mf_36 & 0 & 0.318 & 0.602 & 0.163 & 0.273 & 1 & 29 & 40 & 11 & 13 & 94 & 19 \\
\hline mf_37 & 0.492 & 0.256 & 0.478 & 0.119 & 0.27 & 18 & 18 & 18.5 & 8 & 11 & 73.5 & 14 \\
\hline mf_38 & 0.63 & 0.316 & 0.559 & 0.237 & 0.331 & 39 & 27 & 33 & 22 & 23 & 144 & 31 \\
\hline mf_39 & 0.613 & 0.322 & 0.551 & 0.298 & 0.409 & 35 & 32 & 31 & 37 & 37 & 172 & 38 \\
\hline mf_40 & 0.293 & 0.200 & 0.345 & 0.195 & 0.231 & 7 & 10 & 7 & 16.5 & 7 & 47.5 & 5 \\
\hline mf_41 & 0.524 & 0.193 & 0.453 & 0.104 & 0.218 & 20 & 9 & 16 & 7 & 6 & 58 & 10 \\
\hline mf_42 & 0.455 & 0.312 & 0.465 & 0.296 & 0.372 & 15 & 24 & 17 & 35 & 28 & 119 & 26 \\
\hline mf_43 & 0.727 & 0.389 & 0.664 & 0.32 & 0.442 & 42 & 40 & 42 & 38 & 40.5 & 202.5 & 42 \\
\hline Mean & 0.492 & 0.265 & 0.468 & 0.221 & 0.310 & & & & & & & \\
\hline $\begin{array}{l}\text { Std. } \\
\text { Dev }\end{array}$ & 0.159 & 0.104 & 0.156 & 0.098 & 0.114 & & & & & & & \\
\hline
\end{tabular}

The directional distance function value serves as a measure of inefficiency for each fund with a zero value indicating his operation on the frontier in a given time horizon. Since we choose the direction $g=\left(-g_{V},\left|g_{E}\right|\right)$, positive values of $\vec{D}_{g}$ are interpreted as the simultaneous same proportional increase in return and contraction in risk that are feasible. The average performance of funds is rather unstable across time horizons. Inefficiency $\vec{D}_{g}$, is the greatest in 6 months horizon, with a mean of 0.492 and standard deviation $s=0.159$ and is the lowest in 3 years horizon, with a mean of 0.221 and standard deviation of $s=0.098$. Looking at individual results, almost all funds are, to some extent, inefficient. The directional distance function ranges from a low of 0 for few funds to a high of 0.796 for fund 02 in 6 months horizon.

Different results of the directional distance function are due to the variety of the employed time horizons of analysis that are characterised by different market conditions. Therefore we produce an overall accumulative ranking for each fund using the sum of its ranks over the examined periods. We note that the ranking is made in a descending order.

The results of 4-year time horizon are graphically presented in Figure 1. We plot the funds' return and risk of the sample, their projections onto the portfolio frontier using the directional distance function and the points on the frontier of the Optimum (OPT) and the global Minimum Variance Portfolio (MVP) with risk parameters for a risk averse investor $(\mu=1$ and $\rho=2$ ). Briec et al. (2004) have shown through duality theory the coincidence of the Markowitz and the directional distance function efficient frontier. The advantages of this optimisation approach become more obvious through this graphical representation. Moreover, directional distance function does not require the complete estimation of the efficient frontier but exposes the Markowitz efficient frontier by a nonparametric envelopment method, while its efficiency measure may be used for performance ranking. 
Figure 1 Portfolio efficient frontier for 4 years time horizon (see online version for colours)

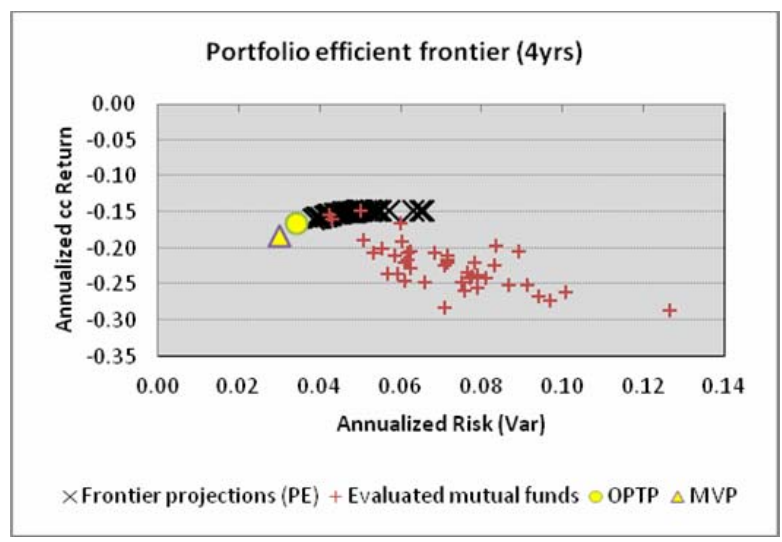

\subsection{Directional distance function vs. BCC-DEA}

Next, we proceed to the comparison of the directional distance function with BCC-DEA results, as calculated by program (2). We use two risk specifications for BCC-DEA; in the quadratic version we use the variance while in the linear version we use volatility i.e. the standard deviation of returns, as risk measure. Furthermore, in order to satisfy the nonnegative requirement of DEA on the returns used, we normalise returns through the addition of a constant. We also note, that for presentation purposes we report their inefficiencies calculated as: $D_{(.)}=1-B C C_{(.)}$. The levels of inefficiency, by fund, DEA model and time horizon, are provided in Appendix in Table A1.We see some differences between the three models, over all time horizons. For example, comparing the linear with the quadratic directional distance function model we notice that both the number of efficient funds and the average efficiency are decreasing significantly.

To examine these differences we use the non-parametric Wilcoxon test since we do not wish to assume that the differences between the two variables of each pair are normally distributed. We report the test statistics and the corresponding $p$-values of each test in Appendix (Tables A2 and A3). The results suggest that there are statistical significant differences in the rankings of quadratic BCC and linear BCC with quadratic directional distance inefficiencies, over all time horizons. This finding implies that ignoring the diversification effect of co-variances in portfolio risk contraction using the linear version of risk i.e. standard deviation, will yield a biased estimate of mutual fund performance. Furthermore, the same conclusion stands when performance benchmarking neglects the potential improvements in returns and it is solely focused in risk contraction using a traditional DEA input contraction version.

\subsection{Directional distance function vs. information ratio for portfolio construction}

Sharpe (1994) presents the information ratio as a generalisation of his ratio as it uses a more relevant benchmark than the Treasury bill. We compute the information ratio as the 
ratio of portfolio returns above the returns of the ASE index to the volatility of those returns. It is used in this study to test the validity of the proposed approach.

Firstly, we compare directional distance rankings with those of IR. We use the Spearman's rho correlation test statistic that is a Pearson correlation coefficient computed on the performance data after converting them to ranks. As we have already mentioned previously, the rankings of directional distance inefficiency indicators have been calculated using their inverse values in order to be consistent with the IR concept i.e. the higher the better.

Table A4 in Appendix shows the matrix of rank correlation coefficients for the two performance indicators along with their $p$-values, across all 5 time horizons. There exists a statistically significant, strong positive association between the two performance indicators used, for 1, 3 and 4 years horizons although there is no significant correlation between the two performance indicators for 6 months and 2 years time horizons. These results are consistent with Murthi et al. (1997) findings, which they showed that standard DEA efficiency measures of US mutual funds are positively correlated with Jensens' alpha and Sharpe index. On contrary Daraio and Simar (2006) results based on nonparametric and robust performance measures (DEA, FDH, order-m) of US mutual funds, are weakly correlated with the same traditional indicators.

Secondly, we compare the performance of portfolios constructed from the ten best funds according to Directional Distance Ratings (DIR) with those constructed from the ten most promising funds according to the IR, using Equal Weighing (NAÏVE), Optimum (OPTP) and MVP models, for all 5 time horizons under consideration. The resulting portfolio performance measures (portfolio risk and return) are reported in Table 3 while the same results in a more detailed form are presented in Appendix (Tables A5-A9).

Table 3 Portfolio performance construction based on individual fund selection criterion

\begin{tabular}{cccccccc}
\hline \multirow{2}{*}{$\begin{array}{c}\text { Time- } \\
\text { horizon }\end{array}$} & & \multicolumn{2}{c}{ Top ten DIR-based criterion } & \multicolumn{2}{c}{ Top ten IR-based criterion } \\
\cline { 3 - 7 } & & NAÏVE & OPTP & $M V P$ & NAÏVE & OPTP & $M V P$ \\
\hline \multirow{2}{*}{$6 \mathrm{~ms}$} & $E\left(r_{p}\right)$ & $-0.37 \%$ & $2.96 \%$ & $-3.37 \%$ & $3.15 \%$ & $3.39 \%$ & $2.78 \%$ \\
& $\operatorname{Var}\left(r_{p}\right)$ & $3.33 \%$ & $3.19 \%$ & $2.44 \%$ & $5.38 \%$ & $4.55 \%$ & $4.35 \%$ \\
\multirow{2}{*}{$1 \mathrm{yr}$} & $E\left(r_{p}\right)$ & $-27.17 \%$ & $-23.42 \%$ & $-25.36 \%$ & $-28.71 \%$ & $-23.24 \%$ & $-23.24 \%$ \\
& $\operatorname{Var}\left(r_{p}\right)$ & $5.85 \%$ & $5.45 \%$ & $5.19 \%$ & $7.67 \%$ & $5.55 \%$ & $5.55 \%$ \\
\multirow{2}{*}{$2 \mathrm{yrs}$} & $E\left(r_{p}\right)$ & $-5.83 \%$ & $-1.34 \%$ & $-6.28 \%$ & $-4.53 \%$ & $-1.34 \%$ & $-1.34 \%$ \\
& $\operatorname{Var}\left(r_{p}\right)$ & $5.41 \%$ & $5.22 \%$ & $4.90 \%$ & $8.18 \%$ & $5.22 \%$ & $5.22 \%$ \\
\multirow{2}{*}{$3 \mathrm{yrs}$} & $E\left(r_{p}\right)$ & $-29.15 \%$ & $-26.92 \%$ & $-26.93 \%$ & $-32.78 \%$ & $-29.84 \%$ & $-29.84 \%$ \\
& $\operatorname{Var}\left(r_{p}\right)$ & $5.24 \%$ & $2.95 \%$ & $2.94 \%$ & $8.99 \%$ & $7.24 \%$ & $7.24 \%$ \\
\multirow{2}{*}{$4 \mathrm{yrs}$} & $E\left(r_{p}\right)$ & $-18.15 \%$ & $-15.50 \%$ & $-15.64 \%$ & $-20.20 \%$ & $-15.40 \%$ & $-15.47 \%$ \\
& $\operatorname{Var}\left(r_{p}\right)$ & $5.26 \%$ & $4.22 \%$ & $4.17 \%$ & $6.88 \%$ & $4.28 \%$ & $4.25 \%$ \\
\hline
\end{tabular}

As far as portfolio risk is concerned, across all time horizons and for the three types of portfolios, the resulting DIR-based portfolios are less risky. In contrasts, IR-based constructed portfolios present, with some notable exceptions, better returns expressed as fewer losses.

As far as the type of portfolio is concerned, DIR-based naïve portfolios present better performance for both performance dimensions in 1, 3 and 4 years time horizons in 
comparison to IR-based naïve portfolios. In comparison to IR-based optimal portfolios, DIR-based optimal portfolios present better results for both performance dimensions in 2 and 3 years time horizons. Finally, in general, minimum variance IR-based portfolios have better returns since they present fewer losses while DIR-based mean variance portfolios constantly have lower risks.

Moreover, according to the detailed results presented in Appendix (Tables A5-A9), we concluded that more diversified portfolios are built through the DIR-based approach compared to the IR-based approach. Indeed, in IR-based optimum portfolios, in 3 out of 5 time horizons there is only one contributor with an aggregated weight of 100 , while in DIR-based optimum portfolios this happen twice. Additionally, three contributors are met in one case of IR-based optimum portfolios, while the same happens in 2 time horizons of DIR-based optimum portfolios.

\section{Conclusions}

The purpose of the present study has been to apply a general method for measuring the efficiency of mutual funds portfolios. Portfolios are ranked by simultaneously looking for risk contraction and mean return augmentation using a quadratic directional distance function framework.

We analyse the differences between the outcomes of rankings based on directional distance function performance indicator and rankings based on two DEA models; the quadratic BCC input and the linear BCC input oriented DEA versions. Moreover, we demonstrate the differences in the obtained portfolio performance results using the directional distance function performance indicator and the information ratio. According to the obtained results portfolios based on the DIR ranking are less risky. This finding could be useful for managers of mutual funds and financial investors, as in decreasing markets investors become more risk averse and seek safer investments in their holdings replacements.

The motivation of the present approach is straightforward. Each mutual fund is evaluated relative to an endogenously created benchmark and it takes into account the diversification effects as measured by the variance of funds returns and the correlations between the mutual funds' returns and other funds returns. Additionally, this method is more flexible as it permits returns to increase and risk to decrease, simultaneously. Finally it was proved that a biased estimate of mutual fund performance results when a standard DEA approach is followed for portfolio selection. Hence directional distancebased performance evaluation can provide a different insight into the subject of nonparametric performance assessment of mutual funds.

\section{References}

Alexakis, P. and Tsolas, I. (2011) 'Appraisal of mutual equity fund performance using data envelopment analysis', Multinational Finance Journal, Vol. 15, Nos. 3/4, pp.273-296.

Artikis, G.P. (2004) 'Performance evaluation of the bond mutual funds operating in Greece', Managerial Finance, Vol. 30, No. 10, pp.1-13.

Babalos, V., Caporale G.M. and Philippas, N. (2012a) 'Efficiency evaluation of Greek equity funds', Research in International Business and Finance, Vol. 26, No. 2, pp.317-333. 
Babalos, V., Philippas, N., Doumpos, M. and Zopounidis, C. (2012b) 'Mutual fund performance appraisal using stochastic multicriteria acceptability analysis', Applied Mathematics and Computation, Vol. 218, pp.5693-5703.

Banker, R., Charnes A. and Cooper, W. (1984) 'Some models for estimating technical and scale inefficiencies in data envelopment analysis', Management Science, Vol. 3, No. 9, pp.1078-1092.

Bollen, N.P.B. (2007) 'Mutual fund attributes and investor behaviour', Journal of Financial and Quantitative Analysis, Vol. 42, No. 3, pp.683-433.

Briec, W., Kerstens, K. and Lesourd, J.B. (2004) 'Single-period portfolio selection, performance gauging, and duality: a variation on the Luenberger shortage function', Journal of Optimization Theory and Applications, Vol. 120, No. 1, pp.1-27.

Chang, K.P. (2004) 'Evaluating mutual fund performance: an application of minimum convex input requirement set approach', Computers and Operations Research, Vol. 31, No. 6, pp.929-940.

Chambers, R.G., Chung, Y. and Färe, R. (1998) 'Profit directional distance functions, and Nerlovian efficiency', Journal of Optimization theory and applications, Vol. 98, No. 2, pp.351-64.

Charnes, A., Cooper, W. and Rhodes, E. (1978) 'Measuring the efficiency of decision making units', European Journal of Operational Research, Vol. 3, No. 6, pp.429-444.

Daraio, C., and Simar, L. (2006) 'A robust nonparametric approach to evaluate and explain the performance of mutual funds,' European Journal of Operational Research, Vol. 175, No. 1, pp.516-542.

Galagedera, D.U.A. and Silvapulle, P. (2002) 'Australian mutual fund performance appraisal using data envelopment analysis', Managerial Finance, Vol. 28, No. 9, pp.60-73.

Gregoriou, G.N. (2003) 'Performance appraisal of funds of hedge funds using data envelopment analysis', The Journal of Wealth Management, Vol. 5, pp.88-95.

Hallerbach, W., Ning, H., Sope, A. and Spronk, J. (2004) 'A framework for managing a portfolio of socially responsible investments', European Journal of Operational Research, Vol. 153, pp.517-529.

Handjinicolaou, G. (1980) 'The performance of Greek mutual funds in the period 1973-76: a case of internationally diversified portfolios', Spoudai, Vol. 11, Nos. 3/4, pp.381-391.

Jensen, C.M. (1968) 'The performance of mutual funds in the period 1945-1964', The Journal of Finance, Vol. 23, No. 2, pp.389-416.

Kerstens, K. and Van De Woestyne, I. (2011) 'Negative data in DEA: a simple proportional distance function approach', Journal of the Operational Research Society, Vol. 62, No. 7, pp.1413-1419.

Markowitz, H.M. (1952) 'Portfolio selection', Journal of Finance, Vol. 7, No. 1, pp.77-99.

Markowitz, H.M. (1956) 'The optimization of a quadratic function subject to linear constraints', Naval Research Logistics Quarterly, Vol. 3, Nos. 1/2, pp.111-133.

Markowitz, H.M. (1959) Portfolio Selection: Efficient Diversification of Investments, John Wiley \& Sons, New York, NY, USA.

McMullen, P.R. and Strong, R.A. (1998) 'Selection of mutual funds using data envelopment analysis', Journal of Business and Economic Studies, Vol. 4, No. 1, pp.1-14.

Milonas, N. (1999) Greek Mutual Funds, Hellenic Bank Association and Sakoulas Editions, Athens, Greece (in Greek).

Morey, M.R. and Morey, R.C. (1999) 'Mutual fund performance appraisals: a multi-horizon perspective with endogenous benchmarking', Omega, Vol. 27, No. 2, pp.241-258.

Murthi, B.P.S, Choi, Y.K. and Desai, P. (1997) 'Efficiency of mutual funds and portfolio performance measurement: a non-parametric approach', European Journal of Operational Research, Vol. 98, No. 2, pp.408-418. 
Ornelas, R.H.J., Junior, F.D.A.S.A. and Fernandes, L.B.J. (2009) Yes, the choice of performance measure does matter for ranking of US mutual funds. Available online at: www.ssrn.com

Pendaraki, K. (2012) 'Mutual fund performance evaluation using data envelopment analysis with higher moments', Journal of Applied Finance and Banking, Vol. 2, No. 5, pp.97-112.

Pendaraki, K., Doumpos M. and Zopounidis, C. (2003) 'Assessing equity funds' performance using a multicriteria methodology: a comparative analysis', South Eastern Europe Journal of Economics, Vol. 1, pp.85-104.

Pendaraki, K. and Spanoudakis, N. (2012) 'An interactive tool for mutual funds portfolio composition using argumentation', Journal of Business, Economics and Finance, Vol. 1, No. 3, pp.33-51.

Pendaraki, K., Zopounidis C. and Doumpos, M. (2005) 'A multicriteria methodology and an application to the Greek market of equity mutual funds', European Journal of Operational Research, Vol. 163, pp.462-481.

Philippas, N.D. (1999) Mutual Funds and Stock Exchange Environment, Globus Invest, Athens, Greece (in Greek).

Roll, R. (1978) 'Ambiguity when performance is measured by the securities market line', The Journal of Finance, Vol. 33, No. 4, pp.151-169.

Sharpe, W.F. (1966) 'Mutual fund performance', Journal of Business, Vol. 1, pp.119-138.

Sharpe, W.F. (1994) 'The Sharpe ratio', Journal of Portfolio Management, Vol. 21, No. 1, pp.49-58.

Sorros, J.N. (2003) 'Return and risk analysis: a case study in equity mutual funds operating in the Greek financial market', Managerial Finance, Vol. 29, No. 9, pp.21-28.

Treynor, J.L. (1965) 'How to rate management of investment funds', Harvard Business Review, Vol. 43, No. 1, pp.63-75.

Xidonas, P., Maurotas, G., Krintas,T., Psarras, J. and Zopounidis, C. (2012) Multicriteria Portfolio Management, Springer, New York, NY, USA. 
Mutual fund performance benchmarking

\section{Appendix}

Table A1 BCC inefficiency scores

\begin{tabular}{|c|c|c|c|c|c|c|c|c|c|c|}
\hline \multirow{2}{*}{$m f$} & \multicolumn{5}{|c|}{$D_{V C}$ by time period } & \multicolumn{5}{|c|}{$D_{S D C}$ by time period } \\
\hline & $6 m s$ & $1 y r$ & $2 y r s$ & $3 y r s$ & 4yrs & $m s$ & $1 y r$ & $2 y r s$ & $3 y r s$ & 4yrs \\
\hline mf_01 & 0.429 & 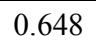 & .616 & 0.647 & .640 & .097 & 0.307 & 0.272 & 0.297 & 0.285 \\
\hline $\mathrm{m}$ & 0 & 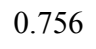 & 0 & 0 & 3 & 7 & 3 & 7 & 4 & 420 \\
\hline mf_03 & 0.547 & 0.553 & 0.56 & 0.606 & 0.605 & 88 & 0 & 0.2 & 0.258 & 252 \\
\hline mf_04 & 0.361 & 0.000 & 0.332 & 0.506 & 0.515 & 0.056 & 0.000 & 0.086 & 0.168 & 0.171 \\
\hline mf_05 & 0.640 & 0.564 & 0.572 & 0.581 & 0.581 & 0.275 & 0.229 & 0.231 & 0.234 & 0.229 \\
\hline mf_06 & 0.707 & 0.662 & 0.680 & 0.710 & 0.703 & 0.354 & 0.321 & 0.336 & 0.363 & 0.351 \\
\hline mf_07 & 0.593 & 0.518 & 0.548 & 0.614 & 0.607 & 0.248 & 0.189 & 0.209 & 0.266 & 0.254 \\
\hline mf_08 & 0.601 & 0 & 0 . & 0.000 & 0.013 & 76 & 0.113 & 0.033 & 0.000 & 0.000 \\
\hline mf_09 & 0.269 & 0.000 & 0.275 & 0.028 & 0.100 & 0.000 & 0.000 & 0.000 & 0.000 & 0.008 \\
\hline mf_10 & 0.601 & 0.571 & 0.600 & 0.647 & 0.641 & 0.240 & 0.235 & 0.258 & 0.297 & 0.286 \\
\hline mf_11 & 0.567 & 0.629 & 0.603 & 0.625 & 0.617 & 0.218 & 0.288 & 0.259 & 0.276 & 0.263 \\
\hline mf_12 & 0.613 & 0.588 & 0.6 & 0.681 & 1 & 57 & 1 & 0.273 & 0.332 & 317 \\
\hline mf_13 & 0.5 & 0. & 0 & 0 & 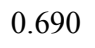 & 75 & 1 & 0.2 & 0.345 & 337 \\
\hline mf_14 & 0.586 & 0.569 & 0.593 & 0.663 & 0.034 & .246 & 0.233 & 0.249 & 0.314 & 0.300 \\
\hline mf_15 & 0.468 & 0.489 & 0.40 & 0.174 & 0.000 & 8 & 0.165 & 0.092 & 0.073 & 0.000 \\
\hline mf_16 & 0.296 & 0.366 & 0.464 & 0.507 & 0.518 & 0.038 & 0.070 & 0.140 & 0.169 & 0.174 \\
\hline mf_17 & 0.622 & 0.593 & 0.613 & 0.636 & 0.630 & 0.259 & 0.255 & 0.269 & 0.287 & 0.276 \\
\hline mf_18 & 0.278 & 0.293 & 0.000 & 0.503 & 0.510 & 0.013 & 0.018 & 0.000 & 0.167 & 0.166 \\
\hline mf_19 & 0.540 & 0.474 & 0.508 & 0.582 & 0.581 & 0.198 & 0.153 & 0.184 & 0.235 & 0.229 \\
\hline mf_20 & 0.6 & 0 & 0 & 0 & & & 0 & 0.2 & 0.265 & 0.258 \\
\hline mf_21 & 0.537 & 0.504 & 0.506 & 0.5 & 7 & 0.220 & 0.178 & 0.174 & 0.171 & 0.164 \\
\hline mf_22 & 0.284 & 0.298 & 0.188 & 0.477 & 0.415 & 0.000 & 0.029 & 0.082 & 0.161 & 0.159 \\
\hline mf_23 & 0.604 & 0.487 & 0.550 & 0.586 & 0.580 & 0.278 & 0.163 & 0.212 & 0.239 & 0.229 \\
\hline mf_24 & 0.725 & 0.663 & 0.602 & 0.614 & 0.613 & 0.367 & 0.322 & 0.259 & 0.265 & 0.259 \\
\hline mf_25 & 0.447 & 0.437 & 0.393 & 0.481 & 0.494 & 0.147 & 0.124 & 0.085 & 0.148 & 0.153 \\
\hline mf_26 & 0.612 & 0.613 & 0.612 & 0.627 & 0.619 & 0.250 & 0.274 & 0.268 & 0.278 & 0.266 \\
\hline mf_27 & 0.611 & 0.613 & 0.612 & 0.627 & 0.619 & 0.249 & 0.274 & 0.268 & 0.278 & 0.266 \\
\hline mf_28 & 0.477 & 0.437 & 0.474 & 0.564 & 0.561 & 0.148 & 0.127 & 0.153 & 0.219 & 0.211 \\
\hline mf_29 & 0.454 & 0.549 & 0.508 & 0.522 & 0.518 & 0.125 & 0.215 & 0.175 & 0.184 & 0.174 \\
\hline mf_30 & 0.629 & 0.577 & 0.549 & 0.578 & 0.576 & 0.302 & 0.240 & 0.211 & 0.232 & 0.225 \\
\hline mf_31 & 0.239 & 0.191 & 0.000 & 0.419 & 0.435 & 0.000 & 0.031 & 0.000 & 0.099 & 0.105 \\
\hline mf_32 & 0.537 & 0.458 & 0.411 & 0.489 & 0.489 & 0.215 & 0.141 & 0.121 & 0.155 & 0.149 \\
\hline mf_33 & 0.598 & 0.492 & 0.400 & 0.374 & 0.411 & 0.256 & 0.167 & 0.090 & 0.087 & 0.086 \\
\hline mf_34 & 0.584 & 0.595 & 0.596 & 0.607 & 0.600 & 0.222 & 0.256 & 0.253 & 0.259 & 0.247 \\
\hline
\end{tabular}


Table A1 BCC inefficiency scores (continued)

\begin{tabular}{lrrrrrrrrrr}
\hline \multirow{2}{*}{$m f$} & \multicolumn{4}{c}{$D_{V C}$ by time period } \\
\cline { 2 - 11 } & $6 m s$ & $1 y r$ & $2 y r s$ & $3 y r s$ & $4 y r s$ & $6 m s$ & $1 y r$ & $2 y r s$ & $3 y r s$ & $4 y r s$ \\
\hline mf_35 & 0.467 & 0.440 & 0.417 & 0.469 & 0.472 & 0.139 & 0.126 & 0.102 & 0.138 & 0.135 \\
mf_36 & 0.000 & 0.688 & 0.682 & 0.675 & 0.664 & 0.000 & 0.348 & 0.338 & 0.326 & 0.310 \\
mf_37 & 0.553 & 0.541 & 0.503 & 0.521 & 0.515 & 0.195 & 0.209 & 0.171 & 0.182 & 0.171 \\
mf_38 & 0.631 & 0.567 & 0.573 & 0.578 & 0.576 & 0.292 & 0.232 & 0.232 & 0.231 & 0.225 \\
mf_39 & 0.613 & 0.549 & 0.573 & 0.625 & 0.621 & 0.287 & 0.216 & 0.232 & 0.276 & 0.267 \\
mf_40 & 0.293 & 0.303 & 0.366 & 0.431 & 0.458 & 0.036 & 0.025 & 0.063 & 0.108 & 0.124 \\
mf_41 & 0.534 & 0.462 & 0.478 & 0.496 & 0.503 & 0.181 & 0.144 & 0.150 & 0.161 & 0.161 \\
mf_42 & 0.455 & 0.456 & 0.486 & 0.546 & 0.544 & 0.153 & 0.139 & 0.158 & 0.203 & 0.196 \\
mf_43 & 0.728 & 0.680 & 0.682 & 0.692 & 0.681 & 0.383 & 0.340 & 0.338 & 0.343 & 0.327 \\
Mean & 0.518 & 0.496 & 0.497 & 0.542 & 0.538 & 0.197 & 0.19 & 0.189 & 0.221 & 0.214 \\
\hline
\end{tabular}

Table A2 Directional distance function vs. quadratic DEA (Wilcoxon signed rank sum test)

\begin{tabular}{cccccc}
\hline & $\vec{D}_{g}(6 m s) v s$. & $\vec{D}_{g}(1 y r) v s$. & $\vec{D}_{g}$ (2yrs) vs. & $\vec{D}_{g}$ (3yrs) vs. & $\vec{D}_{g}$ (4yrs) vs. \\
& $D_{V C}(6 m s)$ & $D_{V C}(1 y r)$ & $D_{V C}(2 y r s)$ & $D_{V C}(3 y r s)$ & $D_{V C}(4 y r s)$ \\
\hline $\mathrm{Z}$ & $-4.548^{\mathrm{a}}$ & $-5.633^{\mathrm{a}}$ & $-5.353^{\mathrm{a}}$ & $-5.646^{\mathrm{a}}$ & $-5.646^{\mathrm{a}}$ \\
$\begin{array}{c}\text { Asymp. Sig. } \\
\text { (two-tailed) }\end{array}$ & .000 & .000 & .000 & .000 & .000 \\
\hline
\end{tabular}

Notes: ${ }^{\mathrm{a}}$ Based on positive ranks.

Table A3 Directional distance function vs. Linear DEA (Wilcoxon signed rank sum test)

\begin{tabular}{cccccc}
\hline & $\vec{D}_{g}(6 m s) v s$. & $\vec{D}_{g}(1 y r) v s$. & $\vec{D}_{g}(2 y r s) v s$. & $\vec{D}_{g}$ (3yrs) vs. & $\vec{D}_{g}(4 y r s) v s$. \\
& $D_{S D C}(6 m s)$ & $D_{S D C}(1 y r)$ & $D_{S D C}(2 y r s)$ & $D_{S D C}(3 y r s)$ & $D_{S D C}(4 y r s)$ \\
\hline $\mathrm{Z}$ & $-5.646^{\mathrm{a}}$ & $-5.496^{\mathrm{a}}$ & $-5.580^{\mathrm{a}}$ & $-.161^{\mathrm{b}}$ & $-5.465^{\mathrm{a}}$ \\
$\begin{array}{c}\text { Asymp. Sig. } \\
\text { (two-tailed) }\end{array}$ & .000 & .000 & .000 & .872 & .000 \\
\hline
\end{tabular}

Notes: a. Based on negative ranks.

b. Based on positive ranks.

Table A4 Spearman rank correlation coefficients for two performance indicators

\begin{tabular}{lccccc}
\hline & $I R(6 m s)$ & $I R(1 y r)$ & $I R(2 y r s)$ & $I R(3 y r s)$ & $I R(4 y r s)$ \\
\hline$\vec{D}_{g}(6 \mathrm{~ms})$ & $.149(.171)$ & $.151(.167)$ & $.437^{* *}(.002)$ & $.095(.273)$ & $.127(.209)$ \\
$\vec{D}_{g}(1 \mathrm{yr})$ & - & $.628^{* *}(.000)$ & $.458^{* *}(.001)$ & $.181(.123)$ & $.232(.067)$ \\
$\vec{D}_{g}(2 \mathrm{yrs})$ & - & - & $.241(.060)$ & $.073(.320)$ & $.153(.164)$ \\
$\vec{D}_{g}(3 \mathrm{yrs})$ & - & - & - & $.666^{* *}(.000)$ & $.701^{* *}(.000)$ \\
$\vec{D}_{g}(4 \mathrm{yrs})$ & - & - & - & - & $.637^{* *}(.000)$ \\
\hline
\end{tabular}

Notes: $\quad * *$ Correlation is significant at the 0.01 level (one-tailed); *Correlation is significant at the 0.05 level (one-tailed); $p$-values in parenthesis. 
Table A5 Portfolio construction based on top ten funds for 6 months horizon

\begin{tabular}{|c|c|c|c|c|c|c|c|c|c|c|c|}
\hline \multicolumn{6}{|c|}{ Based on $\vec{D}_{g}$ ranking } & \multicolumn{6}{|c|}{ Based on IR ranking } \\
\hline & $\operatorname{Var}\left(r_{i}\right)$ & $E\left(r_{i}\right)$ & NAIVE & OPTP & $M V P$ & & $\operatorname{Var}\left(r_{i}\right)$ & $E\left(r_{i}\right)$ & NAIVE & OPTP & $M V P$ \\
\hline mf_36 & 0.072 & 0.077 & 10 & - & - & mf_06 & 0.065 & 0.007 & 10 & - & - \\
\hline mf_01 & 0.062 & 0.054 & 10 & - & - & mf_36 & 0.072 & 0.077 & 10 & 3.84 & - \\
\hline mf_31 & 0.025 & -0.047 & 10 & - & 67.00 & mf_01 & 0.062 & 0.054 & 10 & - & - \\
\hline mf_18 & 0.026 & -0.030 & 10 & - & 22.59 & mf_29 & 0.046 & 0.034 & 10 & 70.27 & - \\
\hline mf_22 & 0.027 & 0.004 & 10 & - & - & mf_34 & 0.049 & 0.019 & 10 & - & - \\
\hline mf_09 & 0.032 & 0.030 & 10 & 100.00 & - & mf_28 & 0.044 & 0.028 & 10 & 25.89 & 100.00 \\
\hline mf_40 & 0.027 & -0.088 & 10 & - & - & mf_11 & 0.059 & 0.036 & 10 & - & - \\
\hline mf_16 & 0.027 & -0.073 & 10 & - & 10.41 & mf_14 & 0.056 & 0.029 & 10 & - & - \\
\hline mf_29 & 0.046 & 0.034 & 10 & - & - & mf_37 & 0.046 & 0.020 & 10 & - & - \\
\hline \multirow[t]{3}{*}{ mf_04 } & 0.030 & 0.003 & 10 & - & - & mf_17 & 0.051 & 0.011 & 10 & - & - \\
\hline & & $E\left(r_{p}\right)$ & -0.37 & 2.96 & -3.37 & & & $E\left(r_{p}\right)$ & 3.15 & 3.39 & 2.78 \\
\hline & & $\operatorname{Var}\left(r_{p}\right)$ & 3.33 & 3.19 & 2.44 & & & $\operatorname{Var}\left(r_{p}\right)$ & 5.38 & 4.55 & 4.35 \\
\hline
\end{tabular}

Table A6 Portfolio construction based on top ten funds for 1 year horizon

\begin{tabular}{lccccccccccc}
\hline \multicolumn{1}{c}{ Based on $\vec{D}_{g}$} & \multicolumn{1}{c}{ Based on IR } \\
\hline & Var $\left(r_{i}\right)$ & $E\left(r_{i}\right)$ & NAIVE & OPTP & MVP & & Var $\left(r_{i}\right)$ & $E\left(r_{i}\right)$ & NAIVE & OPTP & MVP \\
\hline mf_09 & 0.056 & -0.232 & 10 & 86.16 & 7.10 & mf_06 & 0.113 & -0.348 & 10 & - & - \\
mf_04 & 0.052 & -0.245 & 10 & 13.84 & 68.35 & mf_29 & 0.085 & -0.286 & 10 & - & - \\
mf_31 & 0.056 & -0.251 & 10 & - & - & mf_28 & 0.068 & -0.267 & 10 & - & - \\
mf_22 & 0.055 & -0.271 & 10 & - & - & mf_10 & 0.089 & -0.297 & 10 & - & - \\
mf_18 & 0.054 & -0.283 & 10 & - & - & mf_41 & 0.071 & -0.287 & 10 & - & - \\
mf_28 & 0.068 & -0.267 & 10 & - & 24.55 & mf_13 & 0.071 & -0.275 & 10 & - & - \\
mf_13 & 0.071 & -0.275 & 10 & - & - & mf_19 & 0.073 & -0.281 & 10 & - & - \\
mf_19 & 0.073 & -0.281 & 10 & - & - & mf_33 & 0.075 & -0.289 & 10 & - & - \\
mf_41 & 0.071 & -0.287 & 10 & - & - & mf_09 & 0.056 & -0.232 & 10 & 100.00 & 100.00 \\
mf_40 & 0.055 & -0.324 & 10 & - & - & mf_37 & 0.084 & -0.308 & 10 & - & - \\
\hline \multicolumn{1}{c}{$E\left(r_{p}\right)$} & -27.17 & -23.42 & -25.36 & & & $E\left(r_{p}\right)$ & -28.71 & $-23.24-23.24$ \\
& \multicolumn{1}{c}{$\operatorname{Var}\left(r_{p}\right)$} & 5.85 & 5.45 & 5.19 & & & Var $\left(r_{p}\right)$ & 7.67 & 5.55 & 5.55 \\
\hline
\end{tabular}

Table A7 Portfolio construction based on top ten funds for 2 years horizon

\begin{tabular}{cccccccccccc}
\hline \multicolumn{4}{c}{ Based on $\vec{D}_{g}$} & \multicolumn{1}{c}{ Based on IR } \\
\hline & Var $\left(r_{i}\right)$ & $E\left(r_{i}\right)$ & NAIVE & OPTP & MVP & & Var $\left(r_{i}\right)$ & $E\left(r_{i}\right)$ & NAIVE & OPTP & MVP \\
\hline mf_18 & 0.061 & -0.012 & 10 & - & - & mf_06 & 0.112 & -0.081 & 10 & - & - \\
mf_31 & 0.052 & -0.013 & 10 & 100.0 & 26.3 & mf_28 & 0.071 & -0.040 & 10 & - & - \\
mf_22 & 0.062 & -0.015 & 10 & - & - & mf_10 & 0.092 & -0.050 & 10 & - & - \\
mf_09 & 0.050 & -0.074 & 10 & - & 61.5 & mf_19 & 0.077 & -0.035 & 10 & - & - \\
mf_04 & 0.062 & -0.025 & 10 & - & - & mf_36 & 0.116 & -0.048 & 10 & - & - \\
\hline
\end{tabular}


Table A7 Portfolio construction based on top ten funds for 2 years horizon (continued)

\begin{tabular}{|c|c|c|c|c|c|c|c|c|c|c|c|}
\hline \multicolumn{6}{|c|}{ Based on $\vec{D}_{g}$} & \multicolumn{6}{|c|}{ Based on IR } \\
\hline & $\operatorname{Var}\left(r_{i}\right)$ & $E\left(r_{i}\right)$ & NAIVE & OPTP & $M V P$ & & $\operatorname{Var}\left(r_{i}\right)$ & $E\left(r_{i}\right)$ & NAIVE & OPTP & $M V P$ \\
\hline mf_08 & 0.053 & -0.110 & 10 & - & 12.2 & mf_04 & 0.062 & -0.025 & 10 & - & - \\
\hline mf_25 & 0.059 & -0.083 & 10 & - & - & mf_05 & 0.085 & -0.052 & 10 & - & - \\
\hline mf_40 & 0.057 & -0.060 & 10 & - & - & mf_11 & 0.092 & -0.054 & 10 & - & - \\
\hline mf_33 & 0.060 & -0.088 & 10 & - & - & mf_01 & 0.095 & -0.054 & 10 & - & - \\
\hline \multirow[t]{3}{*}{ mf_15 } & 0.060 & -0.100 & 10 & - & - & mf_31 & 0.052 & -0.013 & 10 & 100.00 & 100.00 \\
\hline & & $E\left(r_{p}\right)$ & -5.83 & -1.34 & -6.28 & & & $E\left(r_{p}\right)$ & -4.53 & -1.34 & -1.34 \\
\hline & & $\operatorname{Var}\left(r_{p}\right)$ & 5.41 & 5.22 & 4.90 & & & $\operatorname{Var}\left(r_{p}\right)$ & 8.18 & 5.22 & 5.22 \\
\hline
\end{tabular}

Table A8 Portfolio construction based on top ten funds for 3 years horizon

\begin{tabular}{|c|c|c|c|c|c|c|c|c|c|c|c|}
\hline \multicolumn{6}{|c|}{ Based on $\vec{D}_{g}$} & \multicolumn{6}{|c|}{ Based on IR } \\
\hline & $\operatorname{Var}\left(r_{i}\right)$ & $E\left(r_{i}\right)$ & NAIVE & OPTP & $M V P$ & & $\operatorname{Var}\left(r_{i}\right)$ & $E\left(r_{i}\right)$ & NAIVE & OPTP & $M V P$ \\
\hline mf_08 & 0.052 & -0.267 & 10 & 29.40 & 23.65 & mf_06 & 0.126 & -0.407 & 10 & - & - \\
\hline mf_09 & 0.051 & -0.268 & 10 & 26.10 & 31.04 & mf_29 & 0.077 & -0.297 & 10 & - & - \\
\hline mf_15 & 0.059 & -0.271 & 10 & 44.50 & 45.30 & mf_36 & 0.112 & -0.319 & 10 & - & - \\
\hline mf_33 & 0.061 & -0.288 & 10 & - & - & mf_10 & 0.103 & -0.324 & 10 & - & - \\
\hline mf_22 & 0.072 & -0.290 & 10 & - & - & mf_28 & 0.084 & -0.321 & 10 & - & - \\
\hline mf_29 & 0.077 & -0.297 & 10 & - & - & mf_37 & 0.076 & -0.303 & 10 & - & - \\
\hline mf_41 & 0.072 & -0.298 & 10 & - & - & mf_41 & 0.072 & -0.298 & 10 & 100.00 & 100.00 \\
\hline mf_37 & 0.076 & -0.303 & 10 & - & - & mf_11 & 0.097 & -0.332 & 10 & - & - \\
\hline mf_31 & 0.063 & -0.315 & 10 & - & - & mf_23 & 0.088 & -0.326 & 10 & - & - \\
\hline \multirow[t]{3}{*}{ mf_32 } & 0.071 & -0.317 & 10 & - & - & mf_38 & 0.086 & -0.350 & 10 & - & - \\
\hline & & $E\left(r_{p}\right)$ & -29.15 & -26.92 & -26.93 & & & $E\left(r_{p}\right)$ & -32.78 & -29.84 & -29.84 \\
\hline & & $\operatorname{Var}\left(r_{p}\right)$ & 5.24 & 2.95 & 2.94 & & & $\operatorname{Var}\left(r_{p}\right)$ & 8.99 & 7.24 & 7.24 \\
\hline
\end{tabular}

Table A9 Portfolio construction based on top ten funds for 4 years horizon

\begin{tabular}{cccccccccccc}
\hline \multicolumn{4}{c}{ Based on $\vec{D}_{g}$} & \multicolumn{1}{c}{ Based on IR } \\
\hline & Var $\left(r_{i}\right)$ & $E\left(r_{i}\right)$ & NAIVE & OPTP & MVP & & Var $\left(r_{i}\right)$ & $E\left(r_{i}\right)$ & NAIVE & OPTP & MVP \\
\hline mf_15 & 0.050 & -0.148 & 10 & 6.24 & - & mf_06 & 0.101 & -0.262 & 10 & - & - \\
mf_08 & 0.042 & -0.155 & 10 & 75.97 & 57.45 & mf_10 & 0.083 & -0.196 & 10 & - & - \\
mf_09 & 0.043 & -0.159 & 10 & 17.78 & 42.55 & mf_36 & 0.089 & -0.204 & 10 & - & - \\
mf_22 & 0.060 & -0.165 & 10 & - & - & mf_28 & 0.068 & -0.206 & 10 & - & - \\
mf_33 & 0.051 & -0.189 & 10 & - & - & mf_41 & 0.060 & -0.192 & 10 & - & - \\
\hline
\end{tabular}


Table A9 Portfolio construction based on top ten funds for 4 years horizon (continued)

\begin{tabular}{cccccccccccc}
\hline \multicolumn{1}{c}{ Based on $\vec{D}_{g}$} & \multicolumn{1}{c}{ Based on IR } \\
\hline & $\operatorname{Var}\left(r_{i}\right)$ & $E\left(r_{i}\right)$ & NAIVE & OPTP & MVP & & Var $\left(r_{i}\right)$ & $E\left(r_{i}\right)$ & NAIVE & OPTP & MVP \\
\hline mf_41 & 0.060 & -0.192 & 10 & - & - & mf_15 & 0.050 & -0.148 & 10 & 10.68 & - \\
mf_40 & 0.055 & -0.200 & 10 & - & - & mf_38 & 0.071 & -0.224 & 10 & - & - \\
mf_10 & 0.083 & -0.196 & 10 & - & - & mf_08 & 0.042 & -0.155 & 10 & 89.32 & 100.00 \\
mf_31 & 0.053 & -0.207 & 10 & - & - & mf_23 & 0.071 & -0.210 & 10 & - & - \\
mf_29 & 0.062 & -0.205 & 10 & - & - & mf_01 & 0.083 & -0.224 & 10 & - & - \\
\hline \multicolumn{1}{c}{$E\left(r_{p}\right)$} & -18.15 & -15.50 & -15.64 & & & $E\left(r_{p}\right)$ & -20.20 & -15.40 & -15.47 \\
& \multicolumn{1}{c}{$\operatorname{Var}\left(r_{p}\right)$} & 5.26 & 4.22 & 4.17 & & & $\operatorname{Var}\left(r_{p}\right)$ & 6.88 & 4.28 & 4.25 \\
\hline
\end{tabular}

